\title{
Paradoxical effect of lenalidomide on cytokine/growth factor profiles in multiple myeloma
}

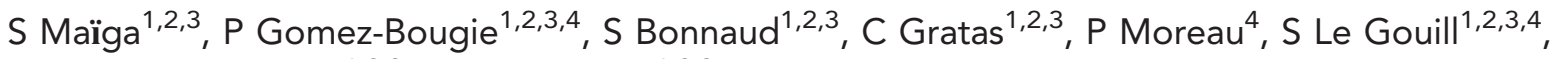 \\ C Pellat-Deceunynck ${ }^{1,2,3}$ and M Amiot ${ }^{*, 1,2,3}$ \\ 1'Inserm, UMR892, Département de Recherche en Cancérologie Nantes/Angers, 8, quai Moncousu, Nantes 44007, France; \\ ${ }^{2}$ Université de Nantes, Nantes 44000, France; ${ }^{3}$ CNRS, UMR 6299, Nantes 44000, France and ${ }^{4}$ Service d'hématologie clinique CHU \\ de Nantes, Nantes, France
}

Background: Lenalidomide is an active immunomodulatory and antiproliferative agent in multiple myeloma. However, the molecular mechanisms driving these activities are not yet fully elucidated. Therefore, we investigated the modulation of the cytokine/growth factor patterns of myeloma cells under LEN treatment.

Methods: Lenalidomide effect on myeloma cell proliferation was investigated in a myeloma cell line collection ( $n=23$ ) by ${ }^{3} \mathrm{H}$-thymidine incorporation. Modulation of the cytokine/growth factor patterns of myeloma cells under LEN treatment was analysed by real-time quantitative PCR.

Results: Lenalidomide inhibits the proliferation of two-thirds of myeloma cell lines independently of their genetic background. We demonstrated that LEN increased TNF- $\alpha$ and IL-8 inflammatory cytokines and insulin-like growth factor-1 (IGF-1) growth factor in both sensitive and resistant myeloma cells to LEN.

Conclusion: Lenalidomide favours a uniform TNF- $\alpha$ and IL-8 inflammatory and IGF-1 secretory profile of myeloma cells, an observation that raises important questions for therapeutic approaches incorporating the agent.

Multiple myeloma (MM) is a presently incurable plasma cell malignancy with a high degree of heterogeneity at presentation and a great variability with regard to the clinical outcome of patients following chemotherapy treatment. Recently, new therapies, such as proteasome inhibitors and immunomodulatory drugs, have been introduced, expanding the options for the treatment of MM. Lenalidomide (LEN) (Revlimid; Celgene, Summit, NJ, USA), a derivative of thalidomide, is a second-generation oral immunomodulatory drug with proven activity against $\mathrm{MM}$ in clinical studies and with a toxicity profile that differs from that of thalidomide. The use of IMiDs alone or as part of combinations plays an increasingly important role in the management of MM patients in all phases of treatment, as induction, consolidation or maintenance. Lenalidomide targets both MM cells and their microenvironment, while also modulating the immune system through the activation of natural killer, CD $4+$ and CD8 + cells, the inhibition of regulatory $\mathrm{T}$ cells and the augmentation of humoral immunity (Raje et al, 2006; Palumbo et al, 2008). The direct anti-MM effect of LEN was shown to occur through the induction of a G1 growth arrest of myeloma cells (Escoubet-Lozach et al, 2009) and was consistently associated with a decrease in interferon regulatory factor 4 (Lopez-Girona et al, 2011). However, it was shown that the inhibitory effect of LEN on myeloma cell proliferation differed from one cell line to another (Lopez-Girona et al, 2011), raising the question of whether there is a correlation with the molecular heterogeneity of MM.

Beside the well-known direct effect of LEN on myeloma proliferation, both the anti-inflammatory and antiangiogenic 
effects of LEN in the bone marrow environment have previously been shown to contribute significantly to the antimyeloma activity of the agent (Raje et al, 2006). Particularly, LEN was selected for its increased capacity to inhibit strongly tumour necrosis factor- $\alpha$ (TNF- $\alpha$ ) secretion by peripheral blood cells compared with thalidomide (Muller et al, 1999). However, the direct antiinflammatory effect of LEN on myeloma cells has not been evaluated previously. Finally, because insulin-like growth factor-1 (IGF-1) has an important role in the pathogenesis of MM, acting not only as a growth, clonogenic and survival factor but also by favouring the homing of myeloma cells to the bone environment and the angiogenesis process (Collette et al, 2007; Menu et al, 2009; Sprinski et al, 2009), we explored the effect of LEN on IGF-1 mRNA synthesis.

\section{MATERIALS AND METHODS}

Cell lines, primary myeloma cells and culture conditions. All human myeloma cell lines (HMCLs) used in this article have been characterised. L363, LP1, OPM-2, SKMM2 and NCI-H929 HMCLs were purchased from DSMZ (Braunschweig, Germany). RPMI8226 and U266 HMCL were obtained from the ATCC (Rockville, MD, USA). JIM-3 and Karpas-620 were kindly provided by Dr I MacLennan (Birmingham, UK) and Dr A Karpas (Cambridge, UK), respectively. MM.1S was a gift from Dr ST Rosen (Chicago, IL, USA). The XG-1, XG-2, XG-3, XG-5, XG-6, XG-7, NAN-1 MDN and BCN HMCLs have been previously established in our laboratory and are cultured in the presence of $3 \mathrm{ng} \mathrm{ml}^{-1}$ of r-IL-6 (Novartis, Basel, Switzerland). Human myeloma cell lines were maintained in RPMI-1640 medium supplemented with 5\% FCS, $2 \mathrm{~mm}$ glutamine and $5 \times 10^{-5} \mathrm{M} 2-\beta \mathrm{ME}$.

Bone marrow samples from patients with MM were collected after informed consent at the Department of Hematology at University Hospital of Nantes or the Intergroupe Francophone du Myelome (IFM). Plasma cells were purified with CD138immunomagnetic beads (Miltenyi Biotech, Bergisch Gladbach, Germany). In all cases, purity of the plasma cells was higher than $90 \%$, as assessed by morphology or CD138 staining.

Bone marrow stromal cells (BMSCs) were obtained after longterm culture of bone marrow samples. Mononuclear cells were plated in DMEM 10\% FCS for 2 or 3 weeks before being used.

Development of LP1 LEN-resistant cell line. LP1 cells were exposed to increased LEN concentrations ranging from 0.1 to $10 \mu \mathrm{M}$ for at least 6 months to achieve stable LEN resistance. Then, the LP1 LEN-resistant (LP1-LR) cell lines were cultured continuously with $30 \mu \mathrm{m}$ LEN. LP1 LEN-resistant cell lines were cultured without LEN for 5 days before being used for experiments.

Cell proliferation assays. Myeloma cells $\left(10^{4}\right.$ cells per well $)$ were cultured in triplicate in 96-well plates for $72 \mathrm{~h}$. Cells were pulsed with $1 \mu \mathrm{Ci}{ }^{3} \mathrm{H}$-thymidine during the past $8 \mathrm{~h}$ of culture. The uptake of ${ }^{3} \mathrm{H}$-thymidine was monitored using a 1450 -Microbeta Jet betacounter (Perkin-Elmer, Waltham, MA, USA).

Cell cycle analysis. After $72 \mathrm{~h}$ treatment with LEN, $10^{6}$ cells were incubated with $10 \mathrm{mg} \mathrm{ml}^{-1} \mathrm{BrdU}$ for $30 \mathrm{~min}$ at $37^{\circ} \mathrm{C}$. Cells were then washed two times in PBS, fixed in 50\% ethanol-PBS and stored at $+4{ }^{\circ} \mathrm{C}$ during $24 \mathrm{~h}$. Cells were treated with $2 \mathrm{~N}$ hydrochloric acid for $30 \mathrm{~min}$ at $37^{\circ} \mathrm{C}$. After several washes, cells were stained with anti-BrdU-FITC Ab overnight at $4{ }^{\circ} \mathrm{C}$. Cells were also stained with $10 \mu \mathrm{g} \mathrm{ml}^{-1}$ propidium iodide. Flow cytometry analysis was performed on a FACS Calibur using Cell Quest Pro software (Becton Dickinson, San Jose, CA, USA).

RNA extraction and quantitative real-time PCR. Total RNA was extracted using Macherey Nagel Nucleospin RNA II Kit according to the manufacturer's recommendation. The RNA concentration was determined by Nanodrop spectrometry (Nanodrop Technologies) and the quality of the RNA was determined in an Agilent 2100 Bioanalyser (Agilent, Palto Alto, CA, USA) using the Labchip RNA 6000 kit. Total RNA $(2 \mu \mathrm{g})$ was reverse transcribed using reverse transcription M-MLV-RT kit (Invitrogen, Life Tchnologies, Saint Aubin, France). The cDNA was diluted to a final concentration of $20 \mathrm{ng} \mu \mathrm{l}^{-1}$, for use in qPCR.

Quantitative PCR was performed in duplicate using the TaqMan Universal PCR Master Mix (Applied Biosystems, Courtaboeuf, France) and the MX3005 instrument (Stratagene, Amsterdam, The Neterlands). TaqMan gene expression assays for TNF- $\alpha$ (Hs00174128_m1), IL-8 (Hs00174103_m1), IGF-1 (Hs00153126_m1) and RPL37a (Hs01102345_m1) were from Applied Biosystems. The following thermal cycling parameters were used: $50{ }^{\circ} \mathrm{C}$ for $2 \mathrm{~min}$ for optimal AmpErase UNG activity and then 40 cycles at $95^{\circ} \mathrm{C}$ for $30 \mathrm{~s}$ and $60{ }^{\circ} \mathrm{C}$ for $1 \mathrm{~min}$. For each primer set, the efficiency was derived from a standard curve (20$0.01 \mathrm{ng}$ ) generated with cDNA obtained from a pool of myeloma cells. Amplification of the housekeeping gene RPL37a was conducted for each sample as an endogenous control. To analyse the data, the relative quantification model described by Pfaffl, 2001 was used with $20 \mathrm{ng}$ sample of LP-1 as calibrator.

Bioassays of TNF- $\alpha$ activity. Myeloma-conditioned media were collected from culture of myeloma cells $\left(0.5 \times 10^{6}\right.$ cells per ml $)$ treated or not by LEN $(10 \mu \mathrm{M})$ for $48 \mathrm{~h}$. WEHI-164 cells $\left(3 \times 10^{4}\right.$ cells per well) were incubated with $50 \mu \mathrm{l}$ of myeloma conditioned media for $24 \mathrm{~h}$ at $37^{\circ} \mathrm{C}$ with $5 \% \mathrm{CO}_{2}$. For calibration, WEHI-164 cells were incubated with various concentrations (12.5-800 $\mathrm{pg} \mathrm{ml}^{-1}$ ) of human TNF- $\alpha$ under the same conditions. At the end of the incubation, the viability of cells was determined by MTT reduction method.

\section{RESULTS}

We first examined the in vitro antiproliferative activity of LEN by the ${ }^{3} \mathrm{H}$-thymidine incorporation assay in a large panel of HMCLs $(n=23)$ representative of the molecular heterogeneity of MM. The following cell lines were investigated: NCI-H929, OPM-2, LP-1, XG7 and JIM-3 (MMSET translocation), BCN, NAN-1, L363, MM.1S, XG-6, RPMI-8226 and JJN3 (C-MAF or MAF B translocation) U266, XG-1, XG-5, Karpas-620, SKMM2, KMS12-PE and MDN (CCND1 translocation), KMM-1 (CCND3 translocation) and XG-2, XG3 and SBN (nonrecurrent translocations) (Moreaux et al, 2011). Lenalidomide treatment induced a dose-dependent growth inhibition in 13 out of 23 HMCLs with $\mathrm{IC}_{50}$ values ranging from 0.15 to $7 \mu \mathrm{M}$ (Figure 1). Ten HMCLs (JIM-3, XG-7, XG-6, RPMI-8226, JJN3, Karpas-620, SKMM2, KMS12-PE, KMM1 and MDN) belonging to different molecular subtypes were resistant to $\operatorname{LEN}\left(\mathrm{IC}_{50}>10 \mu \mathrm{M}\right)$. On the other hand, no correlation was found between the p53 status of HMCLs and the sensitivity to LEN (results not shown). These data indicate that LEN directly inhibits the proliferation of myeloma cell lines independently of their genetic background.

Because the effect of LEN on myeloma proliferation was heterogeneous, we wonder whether a direct anti-inflammatory effect of LEN on myeloma cells could be related to this heterogeneity. Thus, we investigated TNF- $\alpha$ production by both myeloma cell lines and primary purified myeloma cells under LEN treatment. We first confirmed the inhibitory effect of LEN on the production of TNF- $\alpha$ by BMSCs from MM patients using real-time PCR. As reported previously, LEN induces an inhibition of TNF- $\alpha$ mRNA level of $35 \%$ in BMSCs (Figure 2B). While all HMCLs, with the exception of the NCI-H929 cell line, expressed TNF- $\alpha$ mRNA, its levels in HMCLs was weak compared with BMSCs (Figure 2A). Surprisingly, in contrast to the inhibitory effect of LEN in BMSCs, LEN was totally ineffective at inhibiting TNF- $\alpha$ mRNA expression 

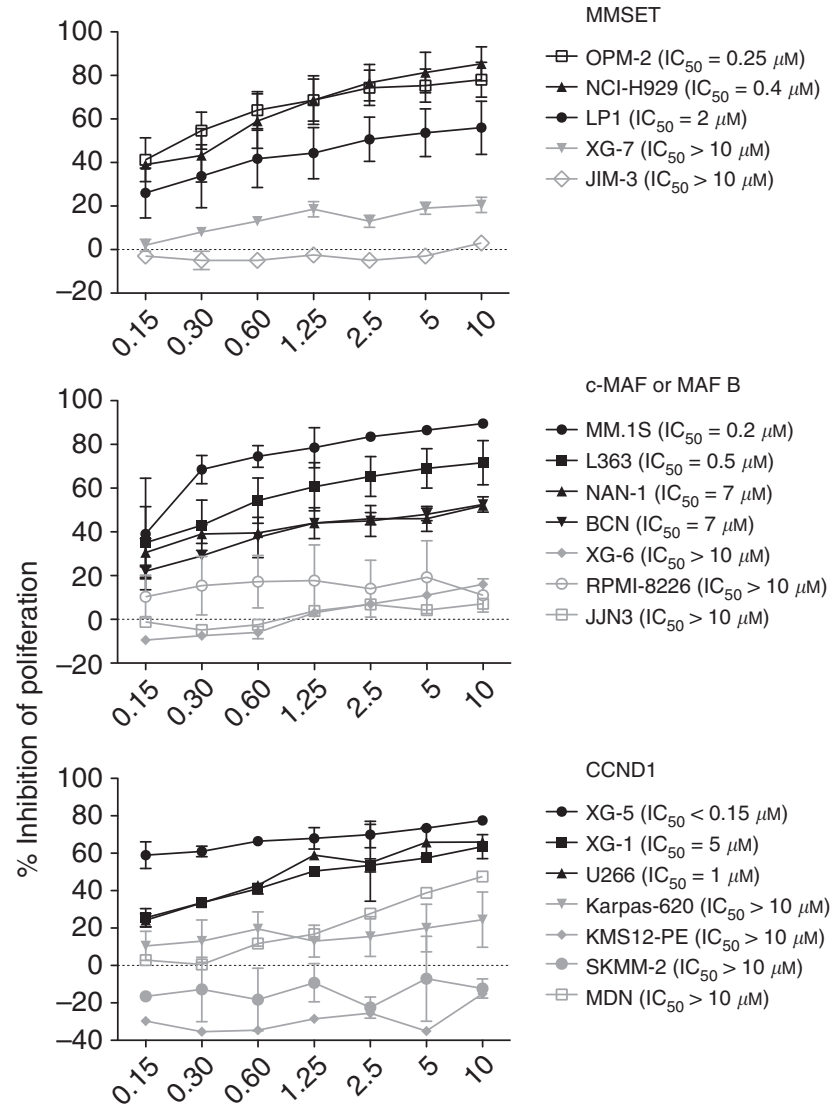

C-MAF or MAF B

- MM.1S $\left(\mathrm{IC}_{50}=0.2 \mu \mathrm{M}\right)$

- L363 $\left(\mathrm{IC}_{50}=0.5 \mu \mathrm{M}\right)$

$\rightarrow \mathrm{NAN}-1\left(\mathrm{IC}_{50}=7 \mu \mathrm{M}\right)$

$\rightarrow \mathrm{BCN}\left(\mathrm{IC}_{50}=7 \mu \mathrm{M}\right)$

$\rightarrow$ XG-6 $\left(\mathrm{IC}_{50}>10 \mu \mathrm{M}\right)$

- RPMI-8226 $\left(\mathrm{IC}_{50}>10 \mu \mathrm{M}\right)$

$\square$ JJN3 $\left(\mathrm{IC}_{50}>10 \mu \mathrm{M}\right)$

CCND1

- XG-5 $\left(\mathrm{IC}_{50}<0.15 \mu \mathrm{M}\right)$

$\rightarrow X \mathrm{XG}-1\left(\mathrm{IC}_{50}=5 \mu \mathrm{M}\right)$

$\leftarrow \operatorname{U} 266\left(\mathrm{IC}_{50}=1 \mu \mathrm{M}\right)$

7 Karpas-620 $\left(\mathrm{IC}_{50}>10 \mu \mathrm{M}\right)$

$\rightarrow \operatorname{KMS} 12-\mathrm{PE}\left(\mathrm{IC}_{50}>10 \mu \mathrm{M}\right)$

- SKMM-2 $\left(\mathrm{IC}_{50}>10 \mu \mathrm{M}\right)$

$\square \operatorname{MDN}\left(\mathrm{IC}_{50}>10 \mu \mathrm{M}\right)$

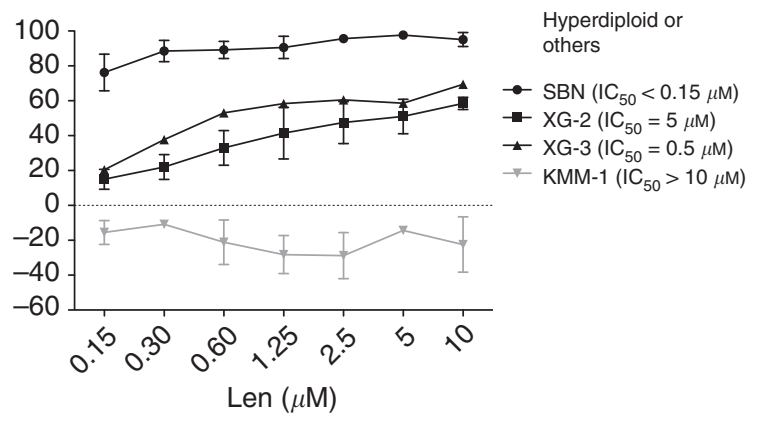

Figure 1. Dose-dependent inhibition of HMCL proliferation by LEN. Human myeloma cell lines were grown in culture media for 3 days in the presence of different concentrations of LEN. Interleukin-6dependent cell lines were cultured in the presence of $3 \mathrm{ng} \mathrm{ml}^{-1}$ of IL-6. Mean values ( \pm s.d.) of $\mathrm{H}^{3}$-thymidine incorporation from three independent experiments were determined and results are expressed as the percentage of inhibition. The half-maximal inhibitory concentration $\left(\mathrm{IC}_{50}\right)$ is indicated for each cell line.

in myeloma cells. In fact, LEN increased TNF- $\alpha$ mRNA levels in 10 out of 12 HMCLs with a median increase of $179 \%$ (range $58-369 \%$, $P=0.006$; Figure 2A). Of note, increased TNF- $\alpha$ mRNA levels induced by LEN were observed both in myeloma cells sensitive and resistant to LEN. Similar increase of TNF- $\alpha$ mRNA levels was observed in all four primary CD138 ${ }^{+}$myeloma cells tested with a median increase of $292 \%$ (range $170-509 \%, P=0.012$; Figure $2 B$ ). To further investigate whether the increase in TNF- $\alpha$ mRNA led to an increase in TNF- $\alpha$ activity in myeloma cell-conditioned supernatant, a bioassay using WEHI cells was performed. This bioassay demonstrated that LEN increased TNF- $\alpha$ activity in both KMS12-PE and XG5 myeloma cells (Figure 2C). Altogether, the results demonstrate the inhibitory effect of LEN on TNF- $\alpha$ production by BMSCs and the promoting effect of LEN on TNF- $\alpha$ production in primary myeloma cells and cell lines.

Of interest, LEN has been previously shown to inhibit the side population of HMCL identified as cancer-initiating cells with stem cell and clonogenic properties (Jakubikova et al, 2011). Because IGF-1 is considered as one of the most important growth and clonogenic factor for myeloma cells, we explored the effect of LEN on IGF-1 mRNA synthesis. We assessed the effect of LEN on IGF-1 mRNA in both myeloma cells and BMSCs. Of note, all HMCLs, with the exception of KMS12-PE and primary myeloma cells, expressed IGF-1 mRNA (Figure 2D). Furthermore, we observed that primary myeloma cells expressed significantly higher levels of IGF-1 mRNA than HMCLs (23-fold, $P=0.0064$ Mann-Whitney test; Figure 2D). While BMSCs also produced IGF-1, the IGF-1 mRNA level is weaker than the one observed in primary MM samples, indicating that the production of IGF-1 is mainly produced because of myeloma cells in contrast to TNF- $\alpha$, which is mainly produced by BMSCs. Our results demonstrate that LEN increased the levels of IGF-1 mRNA in 10 out of 12 HMCLs and in all primary $\mathrm{CD}_{138}{ }^{+}$cells tested $(n=4)$ (Figure $2 \mathrm{E}$ ): the median values of treated cells compared with control cells was of $242 \%$ $(61-545 \%)$ for HMCLs $(P=0.0024$ paired $t$-test) and 160\% (147$281 \%)$ for primary CD138 + cells $(P=0.0706$, paired $t$-test $)$. The upregulation of IGF-1 mRNA level by LEN is observed irrespectively of the inhibitory effect of LEN on HMCLs. Because, these data suggest that LEN treatment seems to favour a secretory profile of myeloma cells, we analyzed the cytokine profile of two LEN-resistant cell lines selected by a similar long-term culture in the presence of LEN, NCI-H929 R10-4 (Lopez-Girona et al, 2011) and LP1-LR. The effect of LEN on cell cycle distribution was investigated in both parental and resistant LP1 HMCL. After $72 \mathrm{~h}$ of LEN treatment, the number of cells in the S phase was strongly reduced (51\% vs 29\%) in LP1, whereas it was not modified in LP1LR (Figure 3A). As indicated in Figure 2A, the parental NCI-H929 did not express TNF- $\alpha$, but an analysis by PCR array showed that NCI-H929 rather expressed IL-8, another proinflammatory cytokine. The cytokine profile (TNF- $\alpha$, IL- 8 and IGF-1) of NCIH929 R10-4 and LP1-LR cell lines in comparison with their respective parental cell line was analysed by qPCR after a 7-day culture without LEN. Our results show that long-term culture in the presence of LEN lead to an increase in TNF- $\alpha$ and IL- 8 mRNA in LP1-LR and NCI-H929 R10-4, respectively (Figure 3B). Furthermore, both NCI-H929 R10-4 and LP1-LR expressed significantly higher levels of IGF-1 mRNA than their respective parental cell lines.

\section{DISCUSSION}

In this study, we first confirmed that the direct antiproliferative effect of LEN is variable from one cell line to another, with an $\mathrm{IC}_{50}$ from 0.15 to $7 \mu \mathrm{M}$. Furthermore, around $40 \%$ of HMCL lines are resistant to LEN treatment. We demonstrated that sensitivity to LEN is not related to the genetic heterogeneity of MM, as resistant cell lines harbour MMSET, MAF or CCND1 translocations. This result is consistent with clinical observations showing that patients with or without $t(4 ; 14)$ responded equally to LEN plus dexamethasone (Dimopoulos et al, 2007).

Altogether, our data on cytokine profile suggest that LEN treatment induced different modifications depending on the cell type, that is, myeloma cells or BMSCs. The effect of LEN on TNF- $\alpha$ is paradoxical since LEN strongly inhibits TNF- $\alpha$ production in the bone marrow environment while inducing it in myeloma cells. The stimulation of TNF- $\alpha$ production by LEN in myeloma cells is observed irrespectively of the proliferative response to LEN. An increasing level of TNF- $\alpha$ after LEN treatment has already been 

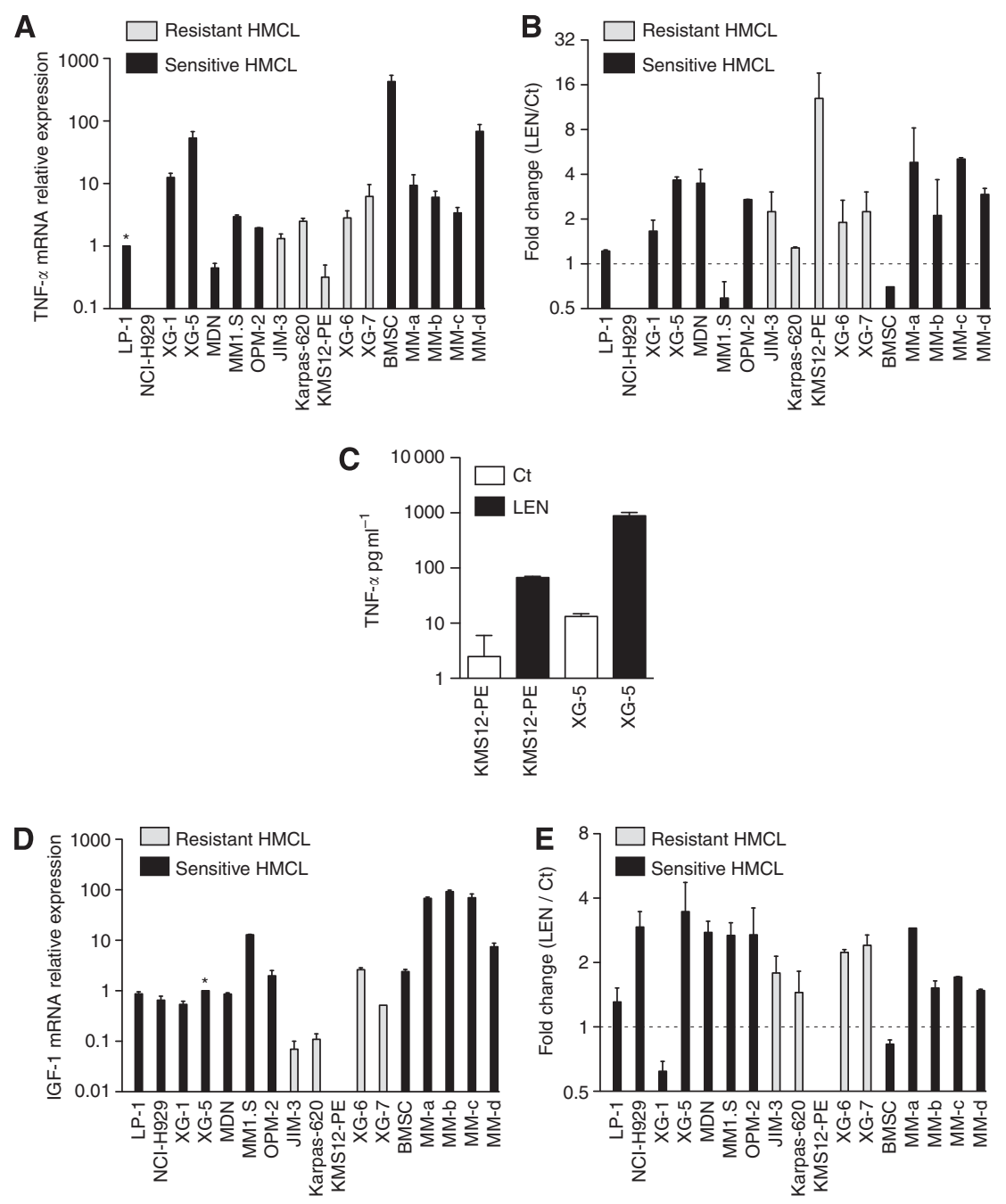

Figure 2. Lenalidomide modulates cytokines and IGF-1 profiles in myeloma cells. (A) Expression of TNF- $\alpha$ mRNA in myeloma cells and BMSC. (B) Modulation of TNF- $\alpha$ mRNA induced by LEN treatment in myeloma cells and BMSC. Human myeloma cell lines, primary CD138 + MM cells and BMSCs were incubated with or without $10 \mu \mathrm{m}$ LEN for $24 \mathrm{~h}$. Total RNA was extracted and reverse-transcribed as described previously. Tumour necrosis factor- $\alpha$ mRNA levels were evaluated by real-time PCR using the TaqMan probe Hs00174128-m1 (Applied Biosystem). The relative expression of TNF- $\alpha$ mRNA was calculated according to the equation of Pfaffl and normalised to LP1. Graphs represent the mean \pm s.d. of mRNA levels from two independent experiments performed in duplicate. (C) Increase of TNF- $\alpha$ production by LEN in myeloma cell lines. (D) Expression of IGF-1 mRNA in myeloma cells and BMSCs. (E) Increase in IGF-1 mRNA levels under LEN treatment. Insulin-like growth factor-1 mRNA levels were evaluated as above using the TaqMan gene expression assay Hs 00153126-m1. Graphs represent the mean \pm s.d. of mRNA levels from two independent experiments performed in duplicate.

reported in CLL patients, consistent with an acute inflammatory response. This acute inflammatory response seems to be related to the critical immunomodulatory activity of LEN (Chanan-Khan et al, 2011). In MM, the production of inflammatory cytokines, such as TNF- $\alpha$ or IL- 8 by myeloma cells under LEN treatment, is weak and likely compensated by the parallel decrease in TNF- $\alpha$ in the bone marrow environment.

Because of the critical importance of the IGF-1 pathway in myeloma development, the increase in IGF-1 mRNA in myeloma cells under LEN treatment raises several questions that might be relevant for clinical investigations. Indeed, LEN enhances IGF-1 mRNA levels in almost all HMCLs and primary myeloma cells tested. The capacity of LEN to enhance IGF-1 mRNA is also well illustrated in HMCLs selected for LEN resistance after long-term culture with increasing doses of LEN. This increase in IGF-1 mRNA could result in the formation of an autocrine growthpromoting loop. Furthermore, IGF-1R expression has previously been shown to be associated with disease severity and poor prognostic groups (Bataille et al, 2005; Sprynski et al, 2009). This autocrine loop may be an adverse event specifically when the proliferation of myeloma cells is not directly inhibited by LEN. Of note, we found that $40 \%$ of HMCLs were resistant to LEN treatment, among them $15 \%$ of presented a weak increase of proliferation under LEN. The proliferation increase is still observed in the absence of serum, underscoring the role of IGF-1 autocrine growth promoting-loop (personal data). This result highlights the importance of finding prognostic markers of the direct antitumour effect of LEN in myeloma cells independently of its ability to modulate the immunological environment and to induce antitumour responses in patients. In the absence of an inhibitory effect of LEN on myeloma cells, we can hypothesise that long-term LEN treatment could lead to the selection of more aggressive cells that might escape the bone marrow environment dependency for growth. Because of recent reports of an increase in the incidence of secondary cancers under LEN maintenance (Attal et al, 2012; McCarthy et al, 2012), it appears reasonable to ask the question of whether the IGF-1/IGF-1R autocrine loop could be involved in the progression of secondary cancers. Indeed, the role of IGF-1 is 
A
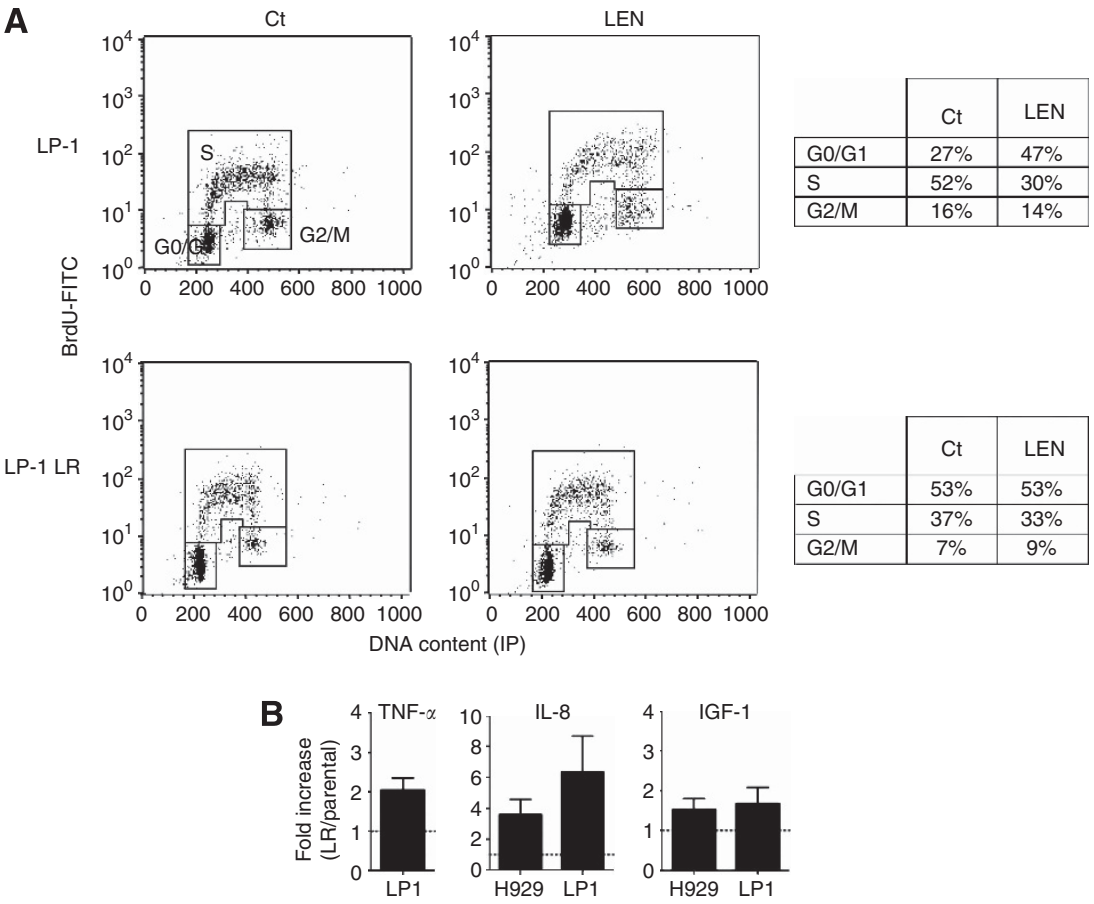

Figure 3. Cytokine profile modifications in LEN-resistant cell lines obtained after long-term culture with increasing doses of LEN. (A) Cell cycle analysis of LP1-LR-resistant cell line. LP1-LR cells were cultured in RMPI-1640 with $5 \%$ foetal calf serum (FCS) in the presence or absence of LEN for 72 h. 5-Bromo-2'-deoxyuridine (BrdU) was incorporated into cells, which were then labelled with propidium iodide before cell cycle analysis by flow cytometry. One representative experiment is shown. (B) Cytokine and growth factor expression levels in resistant cell lines. The NCl-H929 10-4and LP1-LR-resistant cell lines were cultured for 7 days without LEN before RNA extraction. The relative expression of the different mRNA was calculated according to the equation of Pfaffl and normalised to LP1. The TaqMan probe used for IL-8 mRNA detection was Hs 00174103-m1. Graphs represent the mean \pm s.d. of mRNA levels from two independent experiments performed in duplicate.

involved in the progression of many cancers (Pollak, 2008). Consequently, it would be of interest to evaluate IGF-1 levels in the serum of MM patients undergoing LEN maintenance in monotherapy. In addition, our study provides the framework for the evaluation of new combination strategies, such as LEN combined with anti-IGF-1R antibodies for maintenance treatment.

\section{ACKNOWLEDGEMENTS}

This work was supported, in part, by a grant from Celgene corporation and by Actions Cancer 44. SB is supported by grants from région Pays de la Loire (France). We thank Antonia LopezGirona for kindly providing us the NCI-H929 R10-4 LEN-resistant cell line.

\section{AUTHOR CONTRIBUTIONS}

SM designed the experiments, performed the research and analysed the data; PGB, SB, CG analysed the data; PM and SLG provided biological samples and analysed the data; and CP and MA designed the experiments and wrote the paper. All authors critically reviewed and edited the paper.

\section{REFERENCES}

Attal M, Lauwers-Cances V, Marit G, Caillot D, Moreau P, Facon T, Stoppa AM, Hulin C, Benboubker L, Garderet L, Decaux O, Leyvraz S, Vekemans MC, Voillat L, Michallet M, Pegourie B, Dumontet C, Roussel M, Leleu X, Mathiot C, Payen C, Avet-Loiseau H, Harousseau JL. IFM Investigators
(2012) Lenalidomide maintenance after stem-cell transplantation for multiple myeloma. N Engl J Med 366: 1782-1791.

Bataille R, Robillard N, Avet-Loiseau H, Harousseau JL, Moreau P (2005) CD221 (IGF-1R) is aberrantly expressed in multiple myeloma, in relation to disease severity. Haematologica 90: 706-707.

Chanan-Khan AA, Chitta K, Ersing N, Paulus A, Masood A, Sher T, Swaika A, Wallace PK, Mashtare Jr TL, Wilding G, Lee K, Czuczman MS, Borrello I, Bangia N (2011) Biological effects and clinical significance of lenalidomide induced tumour flare reaction in patients with chronic lymphocytic leukaemia: in vivo evidence of immune activation and antitumour response cancer. Br J Haematol 155: 457-467.

Collette M, Descamps G, Pellat-Deceunynck C, Bataille R, Amiot M (2007) Crucial role of phosphatase CD45 in determining signaling and proliferation of human myeloma cells. Eur Cytokine Netw 18: 120-126.

Dimopoulos M, Spencer A, Attal M, Prince HM, Harousseau JL, Dmoszynska A, San Miguel J, Hellmann A, Facon T, Foà R, Corso A, Masliak Z, Olesnyckyj M, Yu Z, Patin J, Zeldis JB, Knight RD (2007) Multiple Myeloma (010) Study Investigators. Lenalidomide plus dexamethasone for relapsed or refractory multiple myeloma. N Engl J Med 357: 2123-2132.

Escoubet-Lozach L, Lin IL, Jensen-Pergakes K, Brady HA, Gandhi AK, Schafer PH, Muller GW, Worland PJ, Chan KW, Verhelle D (2009) Pomalidomide and lenalidomide induce p21 WAF-1 expression in both lymphoma and multiple myeloma through a LSD1-mediated epigenetic mechanism. Cancer Res 69: 7347-7356.

Jakubikova J, Adamia S, Kost-Alimova M, Klippel S, Cervi D, Daley JF, Cholujova D, Kong SY, Leiba M, Blotta S, Ooi M, Delmore J, Laubach J, Richardson PG, Sedlak J, Anderson KC, Mitsiades CS (2011) Lenalidomide targets clonogenic side population in multiple myeloma: pathophysiologic and clinical implications. Blood 117: 4409-4419.

Lopez-Girona A, Heintel D, Zhang LH, Mendy D, Gaidarova S, Brady H, Bartlett JB, Schafer PH, Schreder M, Bolomsky A, Hilgarth B, Zojer N, Gisslinger H, Ludwig H, Daniel T, Jäger U, Chopra R. (2011) Lenalidomide downregulates the cell survival factor, interferon regulatory factor-4, providing a potential mechanistic link for predicting response. Br J Haematol 154: 325-336. 
McCarthy PL, Owzar K, Hofmeister CC, Hurd DD, Hassoun H, Richardson PG, Giralt S, Stadtmauer EA, Weisdorf DJ, Vij R, Moreb JS, Callander NS, Van Besien K, Gentile T, Isola L, Maziarz RT, Gabriel DA, Bashey A, Landau H, Martin T, Qazilbash MH, Levitan D, McClune B, Schlossman R, Hars V, Postiglione J, Jiang C, Bennett E, Barry S, Bressler L, Kelly M, Seiler M, Rosenbaum C, Hari P, Pasquini MC, Horowitz MM, Shea TC, Devine SM, Anderson KC, Linker C (2012) Lenalidomide after stem-cell transplantation for multiple myeloma. N Engl J Med 366: 1770-1781.

Menu E, van Valckenborgh E, van Camp B, Vanderkerken K (2009) The role of the insulin-like growth factor 1 receptor axis in multiple myeloma. Arch Physiol Biochem 115: 49-57.

Moreaux J, Klein B, Bataille R, Descamps G, Maïga S, Hose D, Goldschmidt H, Jauch A, Rème T, Jourdan M, Amiot M, Pellat-Deceunynck C (2011) A high-risk signature for patients with multiple myeloma established from the molecular classification of human myeloma cell lines. Haematologica 96: $574-582$.

Muller GW, Chen R, Huang SY, Corral LG, Wong LM, Patterson RT, Chen Y, Kaplan G, Stirling DI (1999) Amino-substituted thalidomide analogs: potent inhibitors of TNF-alpha production. Bioorg Med Chem Lett 9: $1625-1630$.
Palumbo A, Miguel JS, Sonneveld P, Moreau P, Drach J, Morgan G, Einsele H (2008) Lenalidomide: a new therapy for multiple myeloma. Cancer Treat Rev 34: 283-291.

Pfaffl MW (2001) A new mathematical model for relative quantification in real-time RT-PCR. Nucleic Acids Res 29: e45.

Pollak M (2008) Insulin and insulin-like growth factor signalling in neoplasia. Nat Rev Cancer 8: 915-928.

Raje N, Hideshima T, Anderson KC (2006) Therapeutic use of immunodulatory drugs in the treatment of multiple myeloma. Expert Rev Anticancer Ther 6: 1239-1247.

Sprynski AC, Hose D, Caillot L, Réme T, Shaughnessy Jr JD, Barlogie B, Seckinger A, Moreaux J, Hundemer M, Jourdan M, Meissner T, Jauch A, Mahtouk K, Kassambara A, Bertsch U, Rossi JF, Goldschmidt H, Klein B. (2009) The role of IGF-1as a major growth factor for myeloma cell lines and the prognostic relevance of the expression of its receptor. Blood 113: 4614-4626.

This work is published under the standard license to publish agreement. After 12 months the work will become freely available and the license terms will switch to a Creative Commons AttributionNonCommercial-Share Alike 3.0 Unported License. 